\title{
Dual contraceptive use among adolescents and young adults: correlates and implications for condom use and sexually transmitted infection outcomes
}

\author{
Julia E Hood, ${ }^{1}$ Matthew Hogben, ${ }^{2}$ Maggie Chartier, ${ }^{3}$ Gail Bolan, ${ }^{4}$ \\ Heidi Bauer ${ }^{5}$
}

\begin{abstract}
- Additional material is published online only. To view please visit the journal online (http://dx.doi.org/10.1136/jprhc 2012-100295).
\end{abstract}

For numbered affiliations see end of article

\section{Correspondence to} Ms Julia Hood, Department of Epidemiology, University of Washington, F263 Health Sciences Building, 1959 NE Pacific Street, Seattle, WA 98195-7236, USA; juliahehood@gmail.com

Received 9 January 2012 Revised 19 July 2013 Accepted 23 July 2013 Published Online First 29 November 2013

\section{CrossMark}

To cite: Hood JE, Hogben M, Chartier M, et al. J Fam Plann Reprod Health Care 2014:40:200-207.

\begin{abstract}
Background Simultaneous condom and hormonal contraception usage ('dual method use') maximises protection against pregnancy and sexually transmitted infection (STI), although there is concern that promotion of this strategy could result in diminished condom use and inadvertently increase STI risk. In this study, we (1) assessed how the use of dual methods, versus condoms alone, related to STI and consistency of condom use and (2) described the correlates of dual use.

Methods A sample of 1450 young people aged 12-25 years were surveyed and screened for chlamydia and gonorrhoea at non-clinical sites in two high morbidity Californian counties in 2002-2003. Differences in STI prevalence and reported consistency of condom use were assessed for 'condom only' and 'dual method' users. Correlates of dual use were analysed via multivariate polytomous logistic regression.
\end{abstract}

Results Condom only and dual method users did not significantly differ in terms of STI prevalence or reported consistency of condom use. Sex, age, race and relationship tenure were significant correlates of dual use.

Discussion In these observational data, dual method use did not detrimentally affect STI risk. If interpreted alongside each subgroups' risk patterns for STI and unplanned pregnancy, the correlates of dual use can inform STI and pregnancy prevention interventions.

\section{INTRODUCTION}

Adolescents and young adults are disproportionately affected by unintended pregnancy and sexually transmitted infections (STIs). USA national data show that the unintended pregnancy rate, when restricted to sexually active persons, is highest for teens aged 15-19 years, followed by young people aged $20-24$ years. $^{1}$ For a combination of behavioural, biological, epidemiological and cultural reasons, sexually active adolescents and young adults have the highest rates for the most common STIs. Using national surveillance data, the Centers for Disease Control and Prevention estimate the rates of chlamydia and gonorrhea are four times greater in persons aged 15-24 years relative to the total population. ${ }^{23}$

Although condoms, used properly, are an effective means of preventing STI acquisition, the most effective means of preventing pregnancy include various forms of contraception (e.g. hormonal contraceptives) that confer no protection against STI. ${ }^{45}$ Dual method contraceptive use (i.e. the simultaneous use of condoms and other contraceptive methods) thus provides the maximum conceptual protection against both unintended pregnancies and STIs. Dual method use tends to increase during the teen years and decrease thereafter. ${ }^{6} 7$ Users are more likely to report $\geq 1$ recent sex partners, perceive themselves at risk for STI or HIV, and/or have recently begun a new relationship. ${ }^{8-12}$ While increasing over the past two decades, dual method use nonetheless remains relatively uncommon, with only $9-15 \%$ of sexually active adolescents reporting this behaviour in national surveys. ${ }^{6} 713$

Longitudinal studies assessing condom use before and after the uptake of family 
planning services have found condom use to wane when alternative effective contraceptive methods are used. ${ }^{14}$ ${ }^{15}$ Dramatic reductions in condom use have also been observed among individuals who have adopted a longterm user-independent contraceptive method, such as an intrauterine device (IUD) or sterilisation. ${ }^{4} 9 \begin{array}{ll}9 & 16\end{array}$ Similarly, two cross-sectional studies found lower reported condom use among adolescent oral contraceptive users. ${ }^{11}{ }^{17}$ A more recent cross-sectional study, however, did not observe this same pattern. In fact, the investigators found that African American adolescent females who used oral contraception, compared to their counterparts who did not use oral contraception, were significantly less likely to report unprotected vaginal sex and were less likely to screen positive for an STI. ${ }^{18}$

In this study, we assess the contraceptive and STI prevention strategies reported by a diverse sample of adolescents and young adults residing in California, a state that offers free family planning services to low-income residents through the Family Planning, Access, Care, and Treatment (PACT) programme. [NB. Between 1997 and 2011, Family PACT provided comprehensive reproductive health services to over 1.7 million California residents with incomes $\leq 200 \%$ of the Federal Poverty Line and who do not qualify for public or private insurance. See http://www.familypact.org/Files/Reports-andBriefs/2011-1108_FamPACTPreliminaryReport_508.pdf.] To shed light on the relationship between adopted contraceptive strategy and STI risk, we assessed how the use of dual methods, versus condoms alone, is related to consistency of condom use and STI. For further context, we evaluated the correlates of dual method use with a view to informing interventions and recommendations.

\section{METHODS}

\section{Study design}

Data were collected as part of a cross-sectional study of a community-based chlamydia screening initiative that targeted youth and young adults in high-morbidity communities at non-clinical sites. ${ }^{19}$ The study was jointly funded by the Centers for Disease Control and Prevention and the California Department of Health Services, and it was implemented by the San Bernardino and Stanislaus county health departments. Study protocols were reviewed and approved by the Committee on Human Research at the University of California, San Francisco.

\section{Study population}

The target population included sexually active adolescents and young adults who lived, worked or participated in activities in San Bernardino or Stanislaus County. Participant recruitment was undertaken at multiple sites in areas of high STI incidence, including community centres, schools, drug treatment centres and juvenile detention centres.

\section{Data collection and measures}

Across recruitment venues, standardised protocols were followed for the selection of participants, data collection, testing and treatment, and identical project materials (in English and Spanish) were distributed. Outreach workers explained the nature of the study, potential benefits, possible risks of participation, and alternatives to participation before obtaining verbal consent from study participants. Urine specimens were collected and stored in coolers at all sites and were transported to public health laboratories the same day. In accordance with the manufacturers' instructions, specimens underwent nucleic acid amplification testing (NAAT) for Chlamydia trachomatis and Neisseria gonorrhoeae (hereafter referred to as 'chlamydia' and 'gonorrhoea') using United States Food and Drug Adminstration (FDA)-approved NAAT assays manufactured by either GenProbe or Becton-Dickinson. Participants with positive results were contacted, provided with standard treatment, and asked to notify their partners to encourage them to seek evaluation (Figure 1).

To assess contraceptive use, participants were first asked: "Do you and your most recent partner use birth control? [yes, no, don't know]". Men and women who indicated using birth control were then asked: "What kind of birth control do you use? [condoms, 'the pill', 'the shot', spermicides only, other: specify]", with the response representing the participant's perception of the contraceptive strategy employed in their most recent sexual relationship. All participants were asked how often they used condoms in the past 3 months (never/sometimes/most of the time/always/no sex in last 3 months), as well as if they used a condom at last sex (yes/no/don't know). Respondents who reported condom use on this question or reported using condoms 'most of the time' or 'always' on the condom use consistency question were designated as 'condom users'. In order to limit the 'condom user' group to respondents who appeared to routinely use condoms, respondents who reported 'sometimes' using condoms in the previous 3 months, as well as no condom use with most recent partner, were not included in the 'condom user' group. Respondents who reported using 'the pill', 'the shot' or 'other: the patch' were designated as hormonal contraception (HC) users. Respondents who were designated as $\mathrm{HC}$ and condom users were categorised as 'dual method users'; otherwise, respondents were categorised as 'condom only' or 'HC only' users. Ultimately, respondents were assigned to one of five contraceptive groups: contraceptive non-use, condom only, HC only, dual method, or other method. Of the seven respondents assigned to the 'other' category, six were IUD users and one was an implant user; these seven women were excluded from bivariate and multivariate analyses.

The following independent variables were included in analyses: sex, age, race, duration of most recent 


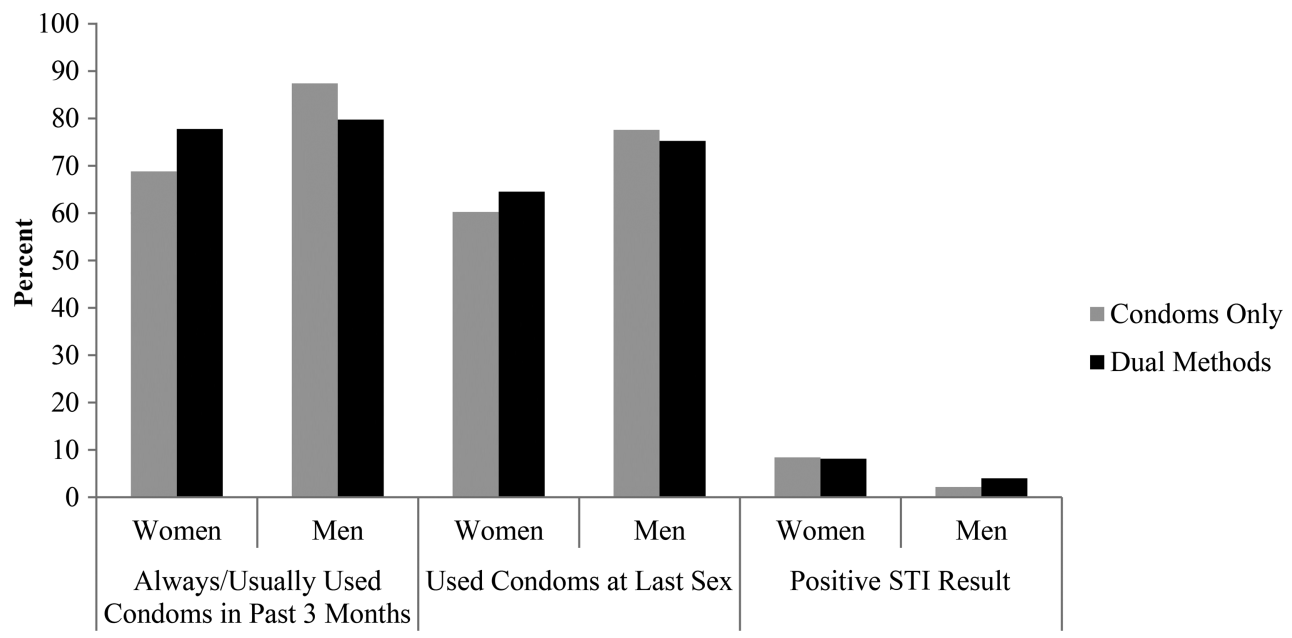

Figure 1 Reported consistency of condom use among 'condom only' and 'dual method' users who participated in an outreach sexually transmitted infection (STI) screening programme in California $(n=1450)$.

relationship, number of sex partners in previous 3 months, and the number of sex partners per year of sexual activity, a composite variable that accounted for the influence of age and age of sexual debut on the number of lifetime sex partners. Duration of relationship was assessed by asking respondents: 'How long have you been having sex with your most recent sex partner?'. The dependent variable, 'STD result', was coded according to whether the participant screened positive for chlamydia or gonorrhoea.

\section{Data analysis}

The distribution of all the aforementioned variables, stratified by gender and summarised for the total sample, was assessed using descriptive statistics. Then two-by-two frequencies and Chi-square $\left(\chi^{2}\right)$ statistics were computed to assess the extent to which 'condom only' and 'dual method' users differed in terms of condom use at last sex, consistency of condom use in the prior 3 months, and having a positive STI test result. These bivariate analyses were stratified by gender; effect modification by gender was assessed using the Breslow-Day test of homogeneity.

To identify correlates of dual method use, we calculated the number and proportion of respondents who comprised each contraceptive group by potential correlates (sex, age, race, duration of sexual relationship, and number of lifetime partners per year of sexual activity). Then, we constructed a multivariate polytomous logistic regression model to assess whether the associations between the independent variables and condom only, HC only and contraceptive non-use differ from that of dual method users. This analytical approach was chosen because it allowed for an unordered categorical response variable to be modelled. Under the null hypothesis [odds ratio $(\mathrm{OR})=1$ ], the independent variable considered is equally associated with the contraceptive types that are compared (e.g. condom only vs dual method). All variables that had a $p$ value $\leq 0.10$ in the bivariate model were retained in the multivariate model. The results from this same analysis stratified by sex are available in an online supplement (Supplemental Tables 1 and 2).

All statistical analyses were performed using Statistical Analysis System (SAS) V.9.2 (SAS Institute, Cary, NC, USA).

\section{RESULTS}

Derivation of analytic sample

Of the 1682 youths who completed the survey, 232 were excluded for the following reasons: older than 25 years $(n=115)$, missing chlamydia result $(n=49)$, sexually naive $(n=67)$, or reported sexual debut at age 4 years or earlier $(n=1)$. A total of 1450 participants were included in the final sample.

\section{Sample description}

The sample was evenly comprised of men and women (Table 1). Although the ages of participants ranged from 12 to 25 years, the average age was 17.6 years with $50 \%$ of the sample aged between 16 and 19 years. Over half of the sample was Hispanic, a quarter was White and $13 \%$ was African American. The majority of participants reported one sex partner in the previous 3 months and an average of 1.7 partners per year of sexual activity. The duration of relationship with most recent sex partner was evenly distributed across the four time frames ( $<1$ month, $1-6$ months, $7-12$ months, $\geq 1$ year). Condoms were the most commonly reported contraceptive method, with $54.0 \%$ of respondents reporting that they used condoms and no other form of contraception. Dual method use, reported by $15.5 \%$ of respondents, was more common than the use of $\mathrm{HC}$ alone, which was reported by $9.2 \%$ of respondents. No contraceptive use at all was reported by $20.9 \%$ of participants. 
Table 1 Characteristics of young people participating in a community-based chlamydia screening programme in California ( $n=1450)$

\begin{tabular}{|c|c|c|c|}
\hline Variable & $\begin{array}{l}\text { Women }(n=734) \\
{[n(\%)]}\end{array}$ & $\begin{array}{l}\text { Men }(n=716) \\
{[n(\%)]}\end{array}$ & $\begin{array}{l}\text { Total }(n=1450) \\
{[n(\%)]}\end{array}$ \\
\hline Mean age (years) & 18.0 & 17.2 & 17.6 \\
\hline \multicolumn{4}{|l|}{ Race } \\
\hline White & $172(23.4)$ & $191(26.7)$ & $363(25.0)$ \\
\hline African American & $99(13.5)$ & $92(12.9)$ & $191(13.2)$ \\
\hline Hispanic & $402(54.8)$ & $348(48.6)$ & $750(51.7)$ \\
\hline Other & $56(7.6)$ & $83(11.6)$ & 139 (9.6) \\
\hline Mean number of partners per year of sexual activity* & 1.4 & 2.1 & 1.7 \\
\hline Mean age at first sex (years) & 14.8 & 13.9 & 14.4 \\
\hline Mean number of lifetime partners & 4.3 & 7.6 & 5.9 \\
\hline \multicolumn{4}{|l|}{ Duration of sexual relationship } \\
\hline$<1$ month & $114(15.5)$ & $222(31.0)$ & $336(23.2)$ \\
\hline $1-6$ months & $191(26.0)$ & $220(30.7)$ & $411(28.3)$ \\
\hline $7-12$ months & $96(13.1)$ & $64 \quad(8.9)$ & $160(11.0)$ \\
\hline$\geq 1$ year & $292(39.8)$ & $114(28.1)$ & $406(28.0)$ \\
\hline Missing & $41(5.6)$ & $96(13.4)$ & $137 \quad(9.5)$ \\
\hline \multicolumn{4}{|l|}{ Contraceptive method with most recent partner } \\
\hline Nothing & $196(26.7)$ & $107(14.9)$ & $303(20.9)$ \\
\hline Condom only & $321(43.7)$ & $462(64.5)$ & $783(54.0)$ \\
\hline Hormonal contraception only & $86(11.7)$ & 47 (6.6) & $133 \quad(9.2)$ \\
\hline Dual method & $124(16.9)$ & $100(14.0)$ & $224(15.5)$ \\
\hline Other & $7(1.0)$ & $0 \quad(0.0)$ & $7 \quad(0.5)$ \\
\hline \multicolumn{4}{|l|}{ Condom use at last sex } \\
\hline Yes & $278(37.9)$ & $420(58.7)$ & $698(48.1)$ \\
\hline No & $439(59.8)$ & $251(35.1)$ & $690(47.6)$ \\
\hline Don't know/missing & $17(2.3)$ & $45(6.3)$ & $62(4.3)$ \\
\hline \multicolumn{4}{|l|}{ Condom use in last 3 months } \\
\hline Never/sometimes & $373(50.8)$ & $205(28.6)$ & $578(39.9)$ \\
\hline Always/usually & $217(29.6)$ & $306(42.7)$ & $523(36.1)$ \\
\hline No sex in last 3 months & $121(16.5)$ & $187(26.1)$ & $308(21.2)$ \\
\hline Missing & $23 \quad(3.1)$ & $18 \quad(2.5)$ & $41 \quad(2.8)$ \\
\hline \multicolumn{4}{|l|}{ STI result } \\
\hline Negative $\mathrm{CT}$ and GC & $663(90.3)$ & $693(96.8)$ & 1356 (93.5) \\
\hline Positive CT only & $59(8.0)$ & $20 \quad(2.3)$ & 79 (5.5) \\
\hline Positive GC only & $6 \quad(0.8)$ & $2(0.3)$ & $8 \quad(0.6)$ \\
\hline Positive $\mathrm{CT}$ and $\mathrm{GC}$ & $2(0.3)$ & $0 \quad(0.0)$ & $2(0.1)$ \\
\hline
\end{tabular}

*Number of lifetime partners per year of sexual activity was calculated by dividing the number of lifetime partners by the number of years since sexual debut. The composite variable provides an estimate of relative sexual activity that is not biased by the age of the respondent.

CT, Chlamydia trachomatis; GC, Neisseria gonorrhoeae; STI, sexually transmitted infection.

Approximately $6 \%$ of the sample screened positive for chlamydia and/or gonorrhoea.

There were several differences between male and female respondents. On average, men in this sample were younger, reported a larger number of lifetime sex partners, reported more consistent condom use, were less likely to report contraceptive non-use, and had a lower prevalence of gonorrhoea and chlamydia, relative to women in this sample.

Reported consistency of condom use and STI test results: condom only users versus dual method users

The proportion of dual method and condom only users with a positive STI test result was very similar (women: $8.1 \%$ vs $8.4 \%$; $p=0.92$; men: $4.0 \%$ vs $2.2 \%, p=0.29$ ) with no evidence of effect modification by gender (Breslow-Day test of homogeneity, $p=0.34)$.

Among women, a larger proportion of dual method users (relative to condom only users) reported always/ usually using condoms $(77.8 \%$ vs $68.8 \% ; p=0.10)$ and using condoms at last sex $(64.5 \%$ vs $60.3 \%$; $p=0.41)$. Among men, a smaller proportion of dual method users (relative to condom only users) reported always/usually using condoms $(79.6 \%$ vs $87.4 \%$; $p=0.09)$ and using condoms at last sex $(75.3 \%$ vs $87.4 \% ; p=0.62)$. While the within-strata comparisons of dual method versus condom only were non- 
significant, these data provide evidence that gender may significantly modify the relationship between single/dual method use and reported condom use consistency (Breslow-Day test of homogeneity, $p=0.02$ ).

\section{Correlates of dual method use}

To explore the correlates of dual method use, we calculated the rates of each contraceptive category stratified by potential correlates and the adjusted ORs for these correlates measured against the odds of dual use (Table 2). Based on this analysis, a larger proportion of men reported using condoms alone than women, $65 \%$ versus $44 \%$, although rates of dual method use were similar across genders (Table 2). Therefore men, relative to women, were more likely to be condom only users than dual users [adjusted odds ratio (aOR) $=1.65 ; 95 \%$ confidence interval $(\mathrm{CI})=1.19-2.30$; $p \leq 0.01)$. However, a larger proportion of women reported no contraceptive use ( $27 \%$ vs $15 \%$ ), and as a result men were less likely to be non-contraceptive users than dual method users $(\mathrm{aOR}=0.63 ; 95 \%$ $\mathrm{CI}=0.43-0.94 ; p \leq 0.05$ ).

The average age differed across the four contraceptive groups, with condom only users being the youngest, followed by dual method users, then non-contraceptive users, and finally HC only users (the oldest group). The pattern of declining condom use and increasing reliance on $\mathrm{HC}$ with age resulted in the finding that with each unit increase in age, participants were significantly more likely to be $\mathrm{HC}$ only users $(\mathrm{aOR}=1.1,95 \% \mathrm{CI}=1.07-1.26 ; p \leq 0.001)$ or contraceptive non-users $(\mathrm{aOR}=1.09,95 \% \mathrm{CI}=1.02$ $1.17 ; p \leq 0.05)$ than dual method users.

For race, the variance in contraceptive use was largely a function of overall differences in the use of HC. White, African American and Hispanic respondents were approximately equally likely to report condom use overall $(71 \%, 72 \%$ and $68 \%$, respectively). However, rates of HC use $(33 \%, 20 \%$ and $22 \%$, respectively) and thus dual method use (22\%, $12 \%$ and $13 \%$, respectively) differed considerably. Consequently, African American and Hispanic youths were more likely, relative to Whites, to be condom only versus dual users, and Hispanics, compared to whites, were more likely to be non-contraceptive users than dual users (Table 2).

Overall, these data showed that as the length of relationship increased, condom use decreased and HC use and contraceptive non-use increased (Figure 2). Compared to participants in long-term relationships, participants in new relationships ( $<1$ month) were more likely to use condoms alone and participants in newer relationships (1-6 months) were less likely to use $\mathrm{HC}$ alone than to use dual methods (Table 2). The number of lifetime sex partners per year of sexual activity did not differ substantially across the four contraceptive groups and was not significantly associated with dual contraceptive use.

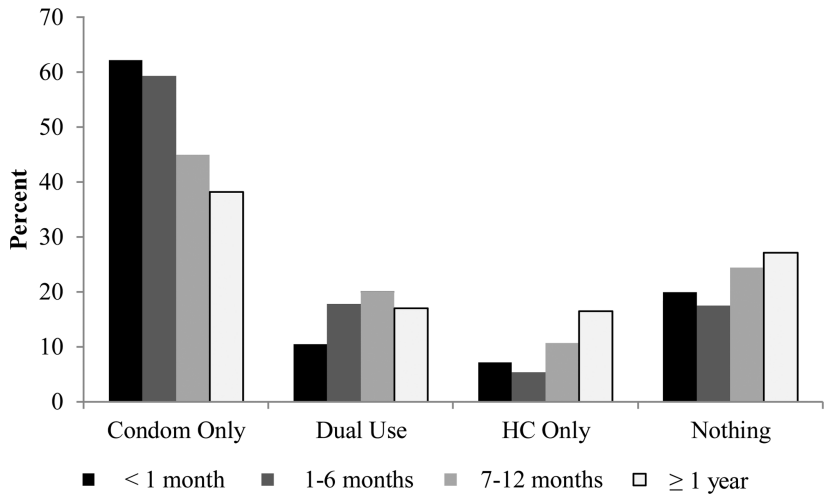

Figure 2 The influence of relationship tenure on chosen contraceptive strategy among participants in an outreach sexually transmitted infection screening programme in California (n=1450). HC, hormonal contraceptive.

When this analysis was stratified by gender, similar results were obtained for men and women (see online supplementary tables).

\section{DISCUSSION}

The disproportionate burden of unintended pregnancy and STI borne by adolescents and young adults has prompted considerable research into the most appropriate contraceptive and STI prevention strategies for this group. In these data, we examined (1) differences in reported condom use and STI prevalence between condom only and dual method users and (2) correlates of dual method use. Our results inform discussions on which contraceptive strategies might be most optimal for adolescents and young adults.

In terms of STI prevalence and reported consistency of condom use, dual method and condom only users did not significantly differ, an interesting counterpoint to previously raised concerns that diminished condom use could result from the promotion of dual use. Therefore, our data did not find that dual method use detrimentally affected STI risk. While the promotion of dual use in community level interventions is unlikely to do harm, our data did not suggest dual use provided benefit beyond either single use strategy. Recognising the limitations of observational data, we nonetheless recommend that interventions be tailored to young people who are most vulnerable in terms of behaviours and service availability. Parallel to our observational data, one randomised control trial found that the intervention group, which exhibited higher rates of dual use, did not differ from the control group in terms of STI and unintended pregnancy. ${ }^{20}$ More observation and intervention studies that assess both STI and pregnancy outcomes are needed to better understand the effectiveness of dual method use (and other strategies) at the community level. Attention should be devoted in future research to which methods and combinations of methods are most effective and cost-effective for which age groups and which levels of experience (i.e. some 
Table 2 Reported contraceptive use by demographic characteristics and sexual experience: descriptive and polytomous regression results

\begin{tabular}{|c|c|c|c|c|c|c|c|c|}
\hline \multirow[b]{2}{*}{$\begin{array}{l}\text { Participant } \\
\text { characteristics }\end{array}$} & \multicolumn{2}{|l|}{ Dual use } & \multicolumn{2}{|c|}{ Condom only } & \multicolumn{2}{|c|}{ Hormonal contraception only } & \multicolumn{2}{|c|}{ Contraception non-use } \\
\hline & $\begin{array}{l}{[n(\%)]} \\
\text { meant }\end{array}$ & aOR $(95 \% \mathrm{Cl})$ & $\begin{array}{l}{[n(\%)]} \\
\text { meant }\end{array}$ & aOR $(95 \% \mathrm{Cl})$ & $\begin{array}{l}{[n(\%)]} \\
\text { meant }\end{array}$ & aOR $(95 \% \mathrm{Cl})$ & $\begin{array}{l}{[n(\%)]} \\
\text { meant }\end{array}$ & aOR $(95 \% \mathrm{Cl})$ \\
\hline Total & $224(15.5)$ & Referent Group & $784(54.0)$ & - & $133(9.2)$ & - & $303(20.9)$ & - \\
\hline \multicolumn{9}{|l|}{ Gender } \\
\hline Female & $124(17.0)$ & & $322(44.2)$ & 1.00 & $86(11.8)$ & 1.00 & $196(26.9)$ & 1.00 \\
\hline Male & $100(14.0)$ & & $462(64.5)$ & $1.65(1.19-2.30)^{\star * *}$ & $47(6.6)$ & $0.90(0.55-1.47)$ & $107(14.9)$ & $0.63(0.43-0.94)^{* * * *}$ \\
\hline Age & 17.6 & & 17.1 & $0.94(0.88-1.01)$ & 19.1 & $1.16(1.07-1.26)^{\star *}$ & 18.3 & $1.09(1.02-1.17)^{\star * * *}$ \\
\hline \multicolumn{9}{|l|}{ Race } \\
\hline White & $65(18.1)$ & & $177(49.3)$ & 1.00 & $38(10.6)$ & 1.00 & $65(18.1)$ & 1.00 \\
\hline African American & $36(18.9)$ & & $116(60.7)$ & $2.88(1.64-5.04)^{\star *}$ & $17(8.9)$ & $1.59(0.72-3.51)$ & $36(18.9)$ & $1.76(0.90-3.45)$ \\
\hline Hispanic & $170(22.7)$ & & $410(54.8)$ & $2.21(1.53-3.18)^{\star}$ & $73(9.8)$ & $1.62(0.96-2.72)$ & $170(22.7)$ & $2.45(1.58-3.78)^{*}$ \\
\hline Other & $31(22.3)$ & & $77(55.4)$ & $1.35(0.78-2.31)$ & $5(3.6)$ & $0.45(0.16-1.30)$ & $31(22.3)$ & $1.61(0.84-3.06)$ \\
\hline \multicolumn{9}{|c|}{ Duration of sexual relationship } \\
\hline$\geq 1$ year & $69(17.2)$ & & $155(38.7)$ & 1.00 & $67(16.7)$ & 1.00 & $110(27.4)$ & 1.00 \\
\hline 7-12 months & $32(20.0)$ & & $72(45.0)$ & $1.00(0.58-1.70)$ & $17(10.6)$ & $0.76(0.37-1.54)$ & $39(24.4)$ & $0.88(0.49-1.60)$ \\
\hline $1-6$ months & $73(17.8)$ & & $244(59.4)$ & $1.24(0.81-1.90)$ & $22(5.4)$ & $0.38(0.20-0.71)^{\star * * *}$ & $72(17.5)$ & $0.70(0.43-1.14)$ \\
\hline$<1$ month & $35(10.5)$ & & $209(62.4)$ & $2.71(1.60-4.59)^{\star *}$ & $24(7.2)$ & $1.12(0.55-2.27)$ & $67(20.0)$ & $1.73(0.96-3.11)$ \\
\hline $\begin{array}{l}\text { Number of partners per } \\
\text { year of sexual activity }\end{array}$ & 1.6 & & 1.7 & $0.89(0.72-1.09)$ & 1.6 & $1.06(0.80-1.42)$ & 2.0 & $1.26(1.00-1.60)$ \\
\hline
\end{tabular}

${ }^{*} p \leq 0.0001,{ }^{* *} p \leq 0.001,{ }^{* * *} p \leq 0.01,{ }^{* * * *} p \leq 0.05$

†The mean is reported for continuous variables; the number and percentage are reported for categorical variables.

NB. Covariates were sex, age, race, relationship tenure and number of partners per year of sexual activity (log scale).

Body typeface indicates an association with a $p$ value $<0.05$.

$\mathrm{aOR}$, adjusted odds ratio; $\mathrm{Cl}$, confidence interval. 
sexually active adolescents may benefit more from a condom promotion approach, whereas others may be best served with dual methods interventions).

In clinical situations, patient-provider discussions on contraceptive and STI prevention strategies would be enhanced through the consideration of patients' risks for pregnancy and STI and patient preferences. Particular attention to relationship status and tenure, among other individual characteristics, appears warranted.

Three previous papers on dual method use and STI risk $^{11}{ }^{17} 18$ categorised respondents as either HC users, a group comprising HC only and dual method users, or non-HC users, a group comprising condom only and contraceptive non-users. When replicating this approach in our data, we found that female non-HC users, relative to $\mathrm{HC}$ users, were more likely to be STI-infected $(\mathrm{aOR}=2.01,95 \% \mathrm{CI}=1.01-4.00)$, a finding that aligned with the analysis conducted by Crosby et al. ${ }^{18}$ In our data, however, the significant association was driven by the high STI prevalence among contraceptive non-users.

Our second analysis of the correlates of dual method use provides insight into the factors that affect decisions made by adolescents and young adults regarding contraception. In this sample, young adolescents more commonly used condoms alone as opposed to dual methods. It may be advantageous to initiate $\mathrm{HC}$ use in this age group, at least among young people at high risk for unintended pregnancy. However, given that national surveys suggest that, on average, adolescents engage in sex acts relatively infrequently, ${ }^{21}$ the potential costs and benefits of initiating $\mathrm{HC}$ at younger ages should be weighed.

Racial minorities were more likely to be condom only users as opposed to dual method users, which may reflect barriers to accessing $\mathrm{HC}$ or negative attitudes towards HC. ${ }^{22} 23$ Expanded insurance coverage and prevention efforts along with the Institute of Medicine's recent recommendation to treat family planning as an essential preventive service for women ${ }^{24}$ should improve the accessibility of family planning services and HC, including for minorities. Nevertheless, these measures do not speak to the numerous barriers to using health care services, such as low health literacy or language/cultural barriers, nor the negative attitudes toward hormonal methods such barriers may cause. ${ }^{22}$ 25-28 Moreover, observational evidence suggests birth control conspiracy beliefs among African Americans are held by a significant minority, and such beliefs are negatively associated with use of provider-dependent methods. ${ }^{26}$ Interventions that seek to increase $\mathrm{HC}$ or dual use among minorities will be best served if they are attentive to formal and informal structural barriers and are carefully tailored to assuage any negative attitudes toward HC.

Duration of one's most recent sexual relationship appeared to be an influential factor on respondents' chosen contraceptive strategy. Specifically, condom use decreased with longer relationship tenure. This pattern, observed here and elsewhere, ${ }^{29}$ may be partly an artefact of the advertised principle of dual use. That is, if one promotes $\mathrm{HC}$ for pregnancy prevention and condoms for STI prevention, a reasonable 'dual user' would discontinue condom use when perceived STI risk declines in a relationship. Because that perceived risk is partly a function of trusting that the relationship is monogamous, the course of intervention is then to help people estimate when the expectation of monogamy is warranted. This approach to intervention could be the substance of a formal behavioural intervention or a facet of clinical care.

There are limitations to this study, namely its crosssectional design, reliance on a convenience sample, selfreported measures and the age of the data. We assessed sexual behaviour and contraceptive use, sensitive topics that may be especially prone to social desirability bias. The possibility that chlamydia and gonorrhoea transmission could have occurred in the presence of condoms may have reduced the statistical power to detect a relationship between chosen contraceptive method and STI transmission. Finally, male participants' capacity to assess their partners' use of $\mathrm{HC}$ may have resulted in inaccurate estimates of $\mathrm{HC}$ and dual method use.

Even with these limitations, several conclusions can be made. First, sexually active adolescents and young adults using no protective methods at all are vulnerable and require services. Condom use had a protective effect and is a logical first point of intervention. Second, because neither condom only users nor HC only users differed from dual method users in terms of STI, there is considerable scope for further observational analysis and intervention. Further research informing the optimal age points for, and correlates of, the maximum effectiveness and cost-effectiveness of dual use, along with subsequent culturally tailored interventions, would be especially useful. Finally, future assessments of contraceptive and STI prevention strategies and their effects should address the composition of comparison groups, as this influences the interpretation of results.

\section{Author affiliations}

${ }^{1}$ Epidemiologist II, Department of Epidemiology, University of Washington, Seattle, WA, USA ${ }^{2}$ Chief, Social \& Behavioral Research \& Evaluation Branch, Division of STD Prevention, Centers for Disease Control and Prevention, Atlanta, GA, USA ${ }^{3}$ National Public Health Clinical Psychologist, Department of Veteran Affairs, San Francisco VA Medical Center, San Francisco, CA, USA

${ }^{4}$ Division Director, Division of STD Prevention, Centers for Disease Control and Prevention, Atlanta, GA, USA

${ }^{5}$ Chief, STD Control Branch, California Department of Public Health, Richmond, CA, USA 
Acknowledgements The authors would like to thank Jean Yokotobi, STD Program Director, and the project coordinators at Stanislaus County Health Services Agency, Sandra Rose and Mark Loeser; Alexander Taylor, STD Program Director, and the project coordinators at the San Bernardino County Department of Public Health STD Control Program, Crystal Jones-Ramos and Heather Cockerill. In addition, they want to thank Holly Howard, Susan Watson, Romni Neiman and Monique Brammeier at the California Department of Public Health STD Control Branch, and Jeanne Moncada and Dr Julius Schachter at the University of California San Francisco Chlamydia Laboratory.

Disclaimer The findings and conclusions in this paper are those of the authors and do not necessarily represent the official position of the Centers for Disease Control and Prevention.

Funding Centers for Disease Control and Prevention (Comprehensive STD Prevention Systems and Infertility Prevention Project Grant Number H25/CCH904362) and California Department of Public Health.

\section{Competing interests None.}

Ethics approval University of California, San Francisco, CA, USA. Provenance and peer review Commissioned; externally peer reviewed.

\section{REFERENCES}

1 Finer LB. Unintended pregnancy among U.S. adolescents: accounting for sexual activity. J Adolesc Health 2010;47:312-314.

2 Centers for Disease Control and Prevention. Sexually Transmitted Disease Surveillance A. Atlanta, GA: U.S. Department of Health and Human Services, November 2009.

3 Centers for Disease Control and Prevention. STD Health Equity - Rates by Age. http://www.cdc.gov/std/healthdisparities/age.htm [accessed 6 October 2013].

4 Pazol K, Kramer MR, Hogue CJ. Condoms for dual protection: patterns of use with highly effective contraceptive methods. Public Health Rep 2010;125:208-217.

5 Peipert J, Redding CA, Blume J, et al. Design of a stagematched intervention trial to increase dual method contraceptive use (Project PROTECT). Contemp Clin Trials 2007;28:626-637.

6 Eaton DK, Kann L, Kinchen S, et al. Youth risk behavior surveillance - United States, 2009. MMWR Surveill Summ 2010;59:1-142.

7 Mosher WD, Martinez GM, Chandra A, et al. Use of contraception and use of family planning services in the United States: 1982-2002. Adv Data 2004;10:1-36.

8 Harvey SM, Henderson JT, Branch MR. Protecting against both pregnancy and disease: predictors of dual method use among a sample of women. Women Health 2004;39:25-43.

9 Cushman LF, Romero D, Kalmuss D, et al. Condom use among women choosing long-term hormonal contraception. Fam Plan Perspect 1998;30:240-243.

10 Santelli JS, Warren CW, Lowry R, et al. The use of condoms with other contraceptive methods among young men and women. Fam Plann Perspect 1997;29:261-267.

11 Lindberg LD, Ku L, Sonenstein FL. Adolescent males' combined use of condoms with partners' use of female contraceptive methods. Matern Child Health J 1998;2:201-209.

12 Poppen PJ, Reisen CA. Women's use of dual methods of sexual self-protection. Women Health 1999;30:53-66.

13 Anderson JE, Santelli J, Gilbert BC. Adolescent dual use of condoms and hormonal contraception - trends and correlates 1991-2001. Sex Transm Dis 2003;30:719-722.
14 Frank ML, Poindexter AN, Cox CA, et al. A cross-sectional survey of condom use in conjunction with other contraceptive methods. Women Health 1995;23:31-46.

15 Rodrigues I, Dedobbeleer N, Turcot C. Use of condoms by adolescents seeking oral contraceptives in the Montreal area [in French]. Can J Public Health 2005;96:438-442.

16 Sangi-Haghpeykar H, Poindexter AN. Planned condom use among women undergoing tubal sterilization. Sex Transm Dis 1998;25:335-341.

17 Roye CF. Condom use by Hispanic and African-American adolescent girls who use hormonal contraception. J Adolesc Health 1998;23:205-211.

18 Crosby RA, DiClemente RJ, Wingood GM, et al. Oral contraceptive use may not preclude condom use: a study of non-pregnant African-American adolescent females. Sex Transm Infect 2007;83:216-218.

19 Morris SR, Bauer HM, Chartier M, et al. Relative efficiency of chlamydia screening in non-clinical settings in two California counties. Int J STD AIDS 2010;21:52-56.

20 Peipert JF, Redding CA, Blume JD, et al. Tailored intervention to increase dual-contraceptive method use: a randomized trial to reduce unintended pregnancies and sexually transmitted infections. Am J Obstet Gynecol 2008;198:630 e631-e638.

21 Abma JC, Martinez GM, Mosher WD, et al. Teenagers in the United States: sexual activity, contraceptive use, and childbearing, 2002. Vital Health Stat 2004;23:1-48.

22 Gilliam ML, Davis SD, Neustadt AB, et al. Contraceptive attitudes among inner-city African American female adolescents: barriers to effective hormonal contraceptive use. J Pediatr Adolesc Gynecol 2009;22:97-104.

23 Dehlendorf C, Rodriguez MI, Levy K, et al. Disparities in family planning. Am J Obstet Gynecol 2010;202: 214-220.

24 Institute of Medicine (IOM). Clinical Preventive Services for Women: Closing the Gaps. Washington, DC: The National Academies Press, 2011.

25 Clark LR, Barnes-Harper KT, Ginsburg KR, et al. Menstrual irregularity from hormonal contraception: a cause of reproductive health concerns in minority adolescent young women. Contraception 2006;74:214-219.

26 Thorburn S, Bogart LM. Conspiracy beliefs about birth control: barriers to pregnancy prevention among African Americans of reproductive age. Health Educ Behav 2005;32:474-487.

27 Grossman D, Fernandez L, Hopkins K, et al. Perceptions of the safety of oral contraceptives among a predominantly Latina population in Texas. Contraception 2010;81:254-260.

28 Guendelman S, Denny C, Mauldon J, et al. Perceptions of hormonal contraceptive safety and side effects among low-income Latina and non-Latina women. Matern Child Health J 2000;4:233-239.

29 Sayegh MA, Fortenberry JD, Shew M, et al. The developmental association of relationship quality, hormonal contraceptive choice and condom non-use among adolescent women. J Adolesc Health 2006;39:388-395.

30 Heffron R, Donnell D, Rees H, et al. Partners in Prevention HSV/HIV Transmission Study Team. Use of hormonal contraceptives and risk of HIV-1 transmission: a prospective cohort study. Lancet Infect Dis 2012;12:19-26.

31 Mohllajee AP, Curtis KM, Martins SL, et al. Hormonal contraceptive use and risk of sexually transmitted infections: a systematic review. Contraception 2006;73:154-165. 